\title{
A QUASI-EXPERIMENTAL STUDY ON THE EFFECTIVENESS OF A FUEL-EFFICIENT COOKSTOVE IN REDUCING PERCEIVED RESPIRATORY SYMPTOMS AMONG MOTHERS OF PUROK 6 IN BRGY, SANTA CRUZ, THE PHILIPPINES
}

\author{
BENEDICTO AGUILAR, ZENAS APAL, RIZZA DE JESUS, MONICA ERNI, \\ KARINA LIPARDO, JANINE RAFAEL, LANCE SESE, \& HENRIETTA DELA CRUZ \\ Ateneo School of Medicine and Public Health, \\ Cebu Institute of Medicine, Xavier University, School of Medicine, The Philippines
}

\begin{abstract}
Indoor cooking with solid biomass fuels is a daily practice in $30 \%$ of poor Filipino households, contributing to a $76 \%$ accruable burden of respiratory diseases. As indoor air pollution is a worsening burden in the Philippines, this study aimed to determine whether the use of a Fuel-Efficient Stove (FES) would reduce exposure and perceived respiratory symptoms, as compared with the traditional ThreeStone Fire (TSF) stoves, in two sub-units (30 households each) of Brgy. Sta. Cruz, Sto. Tomas, Batangas. Methodology. The study utilized a quasi-experimental interventional design. A laboratory analysis comparing the FES and TSF carbon monoxide (CO) point emission levels, and performance was done. Mothers aged 25 years old and above using solid biomass fuels indoors were selected using simple random sampling. The participants answered a questionnaire on perceived respiratory symptoms, and $10 \%$ from the experimental group was tested for ambient and stove CO concentrations before and after the stove deployment. Results. Results showed that the FES significantly reduced CO concentrations for both in the laboratory setting (77.18\%) and in the household setting (overall $79.32 \%$ ). The Water Boiling Test for stove efficiency showed that, in the laboratory, the FES boiled water $43.16 \%$ faster, and consumed $27.59 \%$ less wood per minute while heating $60.16 \%$ more water per gram of wood by transmitting $171.43 \%$ more heat to the pot, as compared to the TSF. After the three-month period, there were observed decreases in almost all respiratory symptoms in the experimental group, but these were not statistically significant. Conclusion. The FES was found to be more efficient and produced less emissions but did not significantly decrease respiratory health symptoms in the study population. Keywords: household indoor air pollution, respiratory health, solid biomass fuel use, clean fuelefficient cookstove, user perception.
\end{abstract}

\section{INTRODUCTION}

Household solid fuel combustion is a primary source of indoor air pollution (IAP) in developing countries [1]. IAP is defined as the emission and accumulation of pollutants generally leading to poor ventilation and air exchange [2].

IAP contributes significantly to the burden of disease in the Philippines; morbidity in the Philippines due to lower respiratory infections and pneumonia was above 750,000 cases as of 2006, and mortality due to chronic lower respiratory disease was above 15,000 as of 2000 . Furthermore, $42 \%$ of chronic lower respiratory disease incidences, including morbidity and mortality, can be attributed to environmental factors [3].

Moreover, the population affected by IAP due to the utilization of solid biomass fuel (SBF) mostly comes from the lower socio-economic class, which consists a big part of the Filipino population with $22.3 \%$ of families falling below the poverty threshold in the first quarter of 2012 [4]. Arcenas et al. [5]. found that the total costs for morbidity and mortality in the Philippines due to Acute Lower Respiratory Infection and Chronic Obstructive Pulmonary Disease (COPD), along with tuberculosis and lung cancer, were estimated to be 
up to 435 million USD. These economic and health effects of IAP stress the need for an intervention to reduce IAP levels in the Philippines. The segment of the population with less access to health care is also the most at risk to hazardous exposure. This reiterates the need for an intervention that reduces IAP that is accessible to the lower socio-economic class.

Stove interventions have been used to reduce IAP [6]. Stoves are commercially available and are marketed as economic, fuel-efficient, and having less detrimental health effects due to reduced emissions, but studies have not been conducted on their actual benefits.

The study intervention, Fuel-Efficient Stove (FES), designed by a local sustainable solution engineer, combines the benefits of two design templates into one: (a) the Rocket Stove design, which is efficient in heat transfer, and (b) the Top-Lit Up Draft design, which ensures adequate fuel aeration to facilitate complete combustion. The stove for the study was produced in a pottery manufacturing company in Pampanga; the total cost incurred per FES used in the study was Php 1,428.58, including manufacturing, transportation, professional fee, and other logistical costs. As such, the study aimed to determine whether perceived respiratory health conditions of mothers in selected households were affected by the FES by comparing results from Purok 6 (experimental group) and Purok 2 (control group) in Brgy. Santa Cruz, Sto. Tomas, Batangas.

To achieve this, the following specific objectives were met: (a) the difference in carbon monoxide $(\mathrm{CO})$ point emission levels and performance in laboratory setting was determined between FES and the most commonly used cooking tool in rural Philippines- the three-stone fire (TSF); (b) the current cooking practices involving SBF and cookstove usage, and smoking practices of selected mothers in the two areas, were determined; (c) the difference in perceived respiratory health conditions of control and experimental groups, pre- and postimplementation of the improved stove, was measured; (d) the difference in $\mathrm{CO}$ concentrations between pre- and post-intervention in the experimental group was determined; and (e) the relationship between $\mathrm{CO}$ levels and perceived respiratory health conditions of mothers was determined.

The term mother is operationally defined in the study as the primary or secondary female cook in the household aged 25 years and above. Female cooks of age 25 were chosen for the study population as, according to literature, (a) they are the most exposed to indoor air pollution due to SBF use in the Philippines; and (b) SBF use has the largest health and nonhealth impact among this population.[4]-[6]. User perception was utilized in this study due to the limited available timeframe and resources to support a clinical diagnosis made by spirometry or medical physical examination for correlation. The use of user perception as a metric, as well as its questionnaire, has been validated by the World Health Organization (WHO) as well as other previous studies- the tool used in this study was developed by Winrock International, translated into Filipino and validated for use in Saksena and Hashmi et al. [7], [8]. The tool used screens for possible confounding factors, such as asthma and smoking. The measuring of CO in the households was done on three households $(10 \%)$ of each purok population, following similar methods from Oluwole et al. [10].

This quasi-experimental interventional study can be taken as an integrated solution to the abovementioned problems, testing the veracity of the locally made FES by deploying it in a community, and measuring the user-perceived respiratory health effects of the stove. It will also aid in the assessment of the problem in the Philippines and will pave new ways in finding solutions. It will add to the limited knowledge on IAP in the Philippines, as well as propose a practical action to reduce its negative health impacts. Figs 1 and 2 depict the TSF used by the community and the FES deployed. 


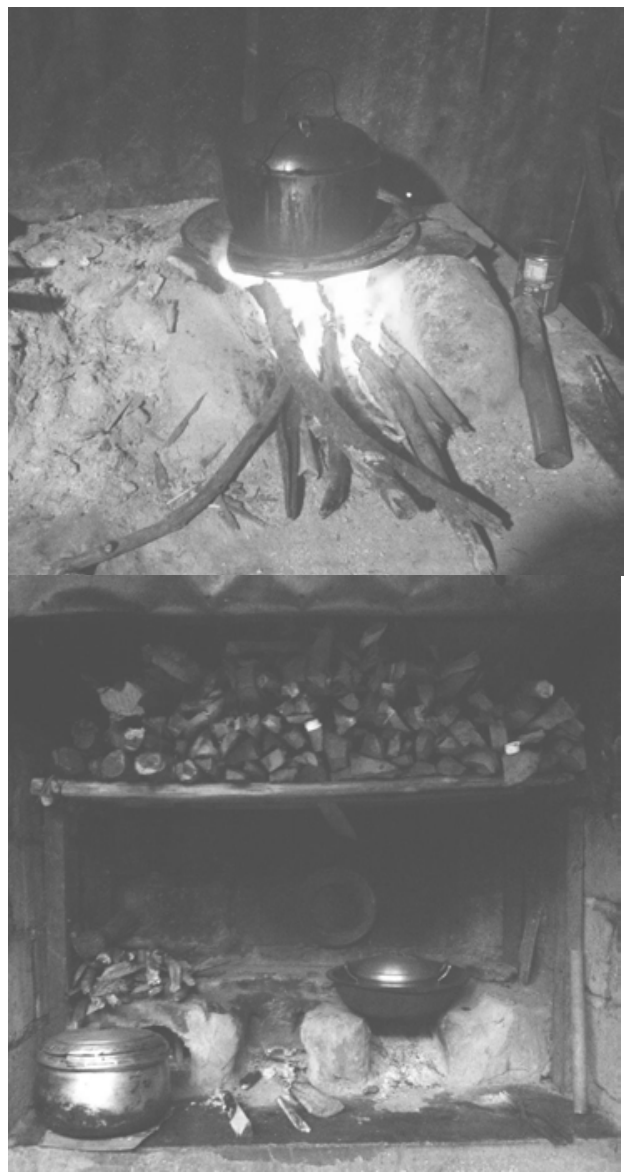

Figure 1: Samples of three-stone fire set-up in control group households.

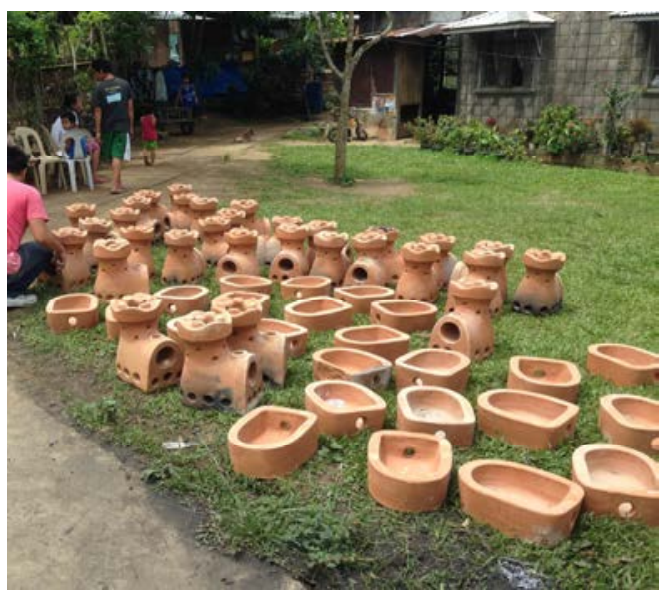

Figure 2: Deployment of fuel-efficient stoves in the experimental group. 


\section{METHODOLOGY}

PHASE 1: Laboratory Analysis. To ensure the non-maleficence of the study, the emissions and efficiencies of both FES and TSF were compared. To test the efficiencies of the stoves, the Water Boiling Test (WBT) [9] was performed on both the FES and TSF, and the data obtained was further compared to pre-existing efficiency values of the TSF. To test the emissions, $\mathrm{CO}$ concentrations were measured from both stoves in a laboratory setting. To conclude that the FES was an effective intervention in terms of efficiency there had to be a decrease in time to boil, a decrease in burning rate, a decrease in specific fuel consumption, and an increase in thermal efficiency. Specific fuel consumption refers to the "ratio of the total amount of wood used to the amount of water "cooked" "while thermal efficiency is the "ratio of the work done by heating and evaporating water to the energy consumed by burning wood" [9].

PHASE 2: Demographic Surveillance and Gathering of Participants. Region IV-A was chosen for the study due to (1) pulmonary diseases being part of the top 5 leading causes of morbidity in the region in 2009 and 2010, (2) the significant usage (33.4\%) of SBF in the area in 2010 considering other regions in the country, and (3) technical and political considerations [7], [11], [12]. Specifically, in Batangas, a province in Region IV-A, the usage of SBF was reported to be $40.94 \%$, higher in indigent households [17]. Within the chosen barangay, qualified participants were determined through visual inspection and a short interview, which determined if they met the following criteria: (1) female, (2) primary or secondary cook of household, (3) aged 25 years old or above, (4) uses SBF to cook, and (5) cooks inside household. From that initial list, simple random sampling was performed to determine the list of final participants. The Pre-Interventional Emissions Field Testing, where the SBF CO concentrations within each participant's household were measured using a CEM-CO 180 Carbon Monoxide Meter, and the Pre-Intervention Survey, which gathered data on the participants' perceived respiratory health conditions, cooking practices, and household practices, was also performed in this phase.

PHASE 3: Intervention Deployment. The stoves were distributed to the households of the experimental group, and the participants were told to use them for the next three months. The households of the control group, on the other hand, were not given any stoves.

PHASE 4: Assessment Phase. A Post-Interventional Emissions Field Testing followed by a Post-Interventional Survey were conducted three months (or nine weeks, one week more than the duration it takes for cough to be considered chronic [11]) after the deployment of the stoves using the same tools that were used before the intervention deployment. These results were compared with the pre-interventional results to determine any significant statistical change.

PHASE 5: Data Analysis. Three analytical tests were used. (1) Wilcoxon Signed Rank Test was used to compare the $\mathrm{CO}$ measurements for the pre- and post-intervention time periods, which were treated as paired samples (e.g. the first minute in the pre- will correspond to the first minute in the post-). (2) The Kruskar-Wallis H Test was used to analyze data on $\mathrm{CO}$ concentrations during the pre- and post-intervention period to show if there was a significant difference among three-time periods (i.e. before, during, and after $\mathrm{CO}$ measurements of the pre- and post- periods). (3) Logistic Regression was done to verify whether the changes in the respiratory health symptoms were due to the intervention. 


\section{RESULTS AND DISCUSSION}

\subsection{Water boiling test for efficiency}

The WBT was conducted using the FES and a TSF. Emissions were also observed before, during, and after the WBT. Three trials for each phase were done; however, the difficulty in maintaining the open fire and the volume of smoke emitted deemed the hot-start and lowpower phases of the open fire WBT un-executable. Only the Phase 1 data was useful for the purposes of the study, as values across literature usually only refer to High Power Cold Start WBT test types. Table 1 shows a comparison of the FES and TSF among specific factors time to boil $(\mathrm{min})$, burning rate $(\mathrm{g} / \mathrm{min})$, specific fuel consumption $(\mathrm{g} / \mathrm{L})$, and thermal efficiency (\%). Table 2 summarizes the $\mathrm{CO}$ measurements taken during the following phases of WBT that immediately follow each other: Cold-Start High-Power Test (Phase 1), HotStart High-Power Test (Phase 2), and Simmer Test (Phase 3). The last phase determines the amount of fuel required to simmer a measured amount of water at just below boiling for 45 minutes.

All three variables (Burning Rate, Specific Fuel Consumption and Thermal Efficiency) showed an improvement in efficiency when using the FES. Essentially, according to the Burning Rate, the FES, when compared to the TSF, consumed $27.59 \%$ less fuel per minute, yet according to Specific Heat Consumption, the FES heated 60.16\% more. Overall, the stove transmitted $171.43 \%$ more heat to the pot as does the TSF. Against literature values, the FES deployed in the study had lower Specific Fuel Consumption than the range provided in literature; it was also above average in thermal efficiency versus other stoves in Southeast Asia [16] and Africa [14]. Overall, the FES was above average in efficiency versus other stove designs, and even above the usual range of efficiency, according to the metrics. Average of CO point levels across the phases of the WBT was at $1.16 \mathrm{ppm} \mathrm{CO}$, much lower than that of the TSF; furthermore, this subscribed to the WHO 2010 Guidelines for Indoor Air Quality of maintaining an average indoor CO level below $24.4 \mathrm{ppm}$. Values across FES WBT CO point level measurements within phases all indicated a large decrease in CO levels between FES and TSF.

\subsection{Emissions field testing}

Shown in Table 3 are the average levels of CO of the $10 \%$ of experimental households. During the pre-intervention emissions field test, the experimental group's averages before, during, and after cooking were $0.97 \pm 0.80 \mathrm{ppm} \mathrm{CO}, 7.98 \pm 6.11 \mathrm{ppm} \mathrm{CO}$, and $0.95 \pm 1.36$ ppm CO, respectively. The highest dispersion values were from the 'during cooking' phase. In the post-intervention emissions field test for the experimental group, the averages for before, during, and after cooking were $0.05 \pm 0.22 \mathrm{ppm} \mathrm{CO}, 1.65 \pm 2.52 \mathrm{ppm} \mathrm{CO}$, and 1.73 $\pm 3.11 \mathrm{ppm}$ CO, respectively. The standard deviation for the 'during cooking' values of the experimental group post-intervention decreased as they used the same cooking technology (FES). Thus, the high standard deviation for the pre-intervention 'during cooking' values was inferred to be due to differences in cooking technology and kitchen characteristics.

Pre- and Post-Intervention Emissions Field Testing Comparison. On average, there was a $79.32 \%$ decrease in $\mathrm{CO}$ concentration during cooking. The difference in the average CO levels of the pre- and post-intervention showed a statistically significant decrease in CO during cooking $(\mathrm{p}=0.000)$ from $7.98 \pm 6.1 \mathrm{ppm}$ to $1.65 \pm 2.52 \mathrm{ppm}$. 
Table 1: Comparison between TSF and FES efficiency.

\begin{tabular}{|l|c|c|c|c|c|c|c|}
\hline & \multicolumn{2}{|c|}{ TSF } & \multicolumn{2}{c|}{$\begin{array}{c}\text { FES (High } \\
\text { Power Cold } \\
\text { Start)* }\end{array}$} & $\begin{array}{c}\text { Percent } \\
\text { difference } \\
\text { between TSF } \\
\text { and FES }\end{array}$ & \multicolumn{2}{c|}{ Literature values** } \\
\hline & Mean & $\begin{array}{c}\text { St. } \\
\text { Dev. }\end{array}$ & Mean & $\begin{array}{c}\text { St. } \\
\text { Dev. }\end{array}$ & & TSF & $\begin{array}{c}\text { Improved } \\
\text { stoves }\end{array}$ \\
\hline $\begin{array}{l}\text { Time to boil } \\
\text { (min) }\end{array}$ & 29.33 & 3.7 & 16.2 & 4.7 & $54.54 \%$ & $\begin{array}{c}25.4 \\
40.66 \\
{[12],[13]}\end{array}$ & $13-17^{* * *}$ \\
\hline $\begin{array}{l}\text { Burning rate } \\
\text { (g/min) }\end{array}$ & 31.9 & 15.1 & 23.1 & 7.2 & $27.59 \%$ & $\begin{array}{c}21-44.02 \\
{[14]}\end{array}$ & - \\
\hline $\begin{array}{l}\text { Specific fuel } \\
\text { consumption } \\
\text { (g/L) }\end{array}$ & 376.3 & 135.3 & 149.9 & 1.3 & $60.16 \%$ & $\begin{array}{c}200-400 \\
* * *\end{array}$ & $200-$ \\
\hline $\begin{array}{l}\text { Thermal } \\
\text { efficiency (\%) }\end{array}$ & 7 & 1 & 19 & 1 & $171.43 \%$ & $\begin{array}{c}8.75-10.4 \\
{[12]}\end{array}$ & $\begin{array}{c}15.44- \\
17.62^{* *}[1 \\
]\end{array}$ \\
\hline
\end{tabular}

* Only High-Power Cold Start could be conducted for the TSF. Thus, only High-Power Cold Start values were displayed for FES in this table.

**These values compare to High Power phase laboratory tests. The FES High Power phase thermal efficiency is $18 \%$.

***Taken from MacCarty, N, Still, D, Ogle, D, \& Drouin, T 2008, Assessing Cook Stove Performance: Field and Lab Studies of Three Rocket Stoves Comparing the Open Fire and Traditional Stoves in Tamil Nadu, India, on Measures of Time to Cook, Fuel Use, Total Emissions, and Indoor Pollution, Aprovecho Research Center, Oregon (Unpublished).

Table 2: Summary of CO measurement during laboratory WBT.

\begin{tabular}{|l|c|c|c|c|c|}
\hline & & $\begin{array}{c}\text { Mean CO point } \\
\text { emissions (ppm) }\end{array}$ & $\begin{array}{c}\text { Mean time } \\
\text { to boil (min) }\end{array}$ & $\begin{array}{c}\text { Peak CO } \\
\text { levels (ppm) }\end{array}$ & St. Dev. \\
\hline $\begin{array}{l}\text { TSF } \\
\text { Phase 1 }\end{array}$ & Before & 0.03 & 28.3 & 1.00 & 0.18 \\
\hline & During & 109.25 & & 519.00 & 105.46 \\
\hline & After & 43.72 & & 662.00 & 110.34 \\
\hline TSF Avg. & & 57.60 & 28.5 & 662.00 & 101.04 \\
\hline $\begin{array}{l}\text { FES } \\
\text { Phase 1 }\end{array}$ & Before & 0 & & & 0 \\
\hline & During & 1.60 & 16.2 & 20.00 & 3.32 \\
\hline & After & 2.35 & & 56.00 & 7.82 \\
\hline $\begin{array}{l}\text { FES } \\
\text { Phase 2 }\end{array}$ & Before & 0.05 & 10.4 & 1.00 & 0.22 \\
\hline & During & 2.43 & & 10.00 & 3.11 \\
\hline & After & 1.62 & & 18.00 & 3.76 \\
\hline $\begin{array}{l}\text { FES } \\
\text { Phase 3 }\end{array}$ & Before & 0.07 & $*$ & 1.00 & 0.25 \\
\hline & During & 1.79 & & 17.00 & 3.33 \\
\hline & After & 0.30 & & 8.00 & 1.15 \\
\hline FES Avg. & & 1.16 & 13.3 & 56.00 & 3.62 \\
\hline
\end{tabular}

* Simmer test must not reach boiling phase. 
Table 3: Pre-intervention (TSF) and post-intervention (FES) average CO concentrations of the experimental group.

\begin{tabular}{|l|c|c|c|c|}
\hline & $\begin{array}{c}\text { Pre-intervention } \\
\text { average (ppm) }\end{array}$ & $\begin{array}{c}\text { Standard } \\
\text { deviation (pre) }\end{array}$ & $\begin{array}{c}\text { Post- } \\
\text { intervention } \\
\text { average (ppm) }\end{array}$ & $\begin{array}{c}\text { Standard } \\
\text { deviation (post) }\end{array}$ \\
\hline $\begin{array}{l}\text { Before } \\
\text { cooking }\end{array}$ & 0.97 & 0.80 & 0.05 & 0.22 \\
\hline $\begin{array}{l}\text { During } \\
\text { cooking }\end{array}$ & 7.98 & 6.11 & 1.65 & 2.52 \\
\hline $\begin{array}{l}\text { After } \\
\text { cooking }\end{array}$ & 0.95 & 1.36 & 1.73 & 3.11 \\
\hline
\end{tabular}

Table 4: Kruskal-Wallis $\mathrm{H}$ test of $\mathrm{CO}$ levels for the experimental group emissions.

\begin{tabular}{|c|c|c|}
\hline $\begin{array}{c}\text { Household and } \\
\text { time period }\end{array}$ & Chi-square & p value \\
\hline \multicolumn{3}{|c|}{ Pre-intervention } \\
\hline Household 1 TSF & 2.37 & 0.306 \\
\hline Household 2 TSF & 38.10 & 0.000 \\
\hline Household 3 TSF & 33.19 & 0.000 \\
\hline \multicolumn{3}{|c|}{ Post-intervention } \\
\hline Household 1 FES & 24.74 & 0.000 \\
\hline Household 2 FES & 15.46 & 0.000 \\
\hline Household 3 FES & 8.14 & 0.017 \\
\hline
\end{tabular}

Table 5: Computed Stove Contribution.

\begin{tabular}{|c|c|c|}
\hline & TSF average & FES average \\
\hline Stove emission (ppm CO) & 7.01 & 1.60 \\
\hline Percent decrease & \multicolumn{2}{|c|}{$77.18 \%$} \\
\hline
\end{tabular}

Kruskal-Wallis $H$ Test for CO Measurements in Experimental Group. There were significant changes in $\mathrm{CO}$ measurements (an obvious spike in $\mathrm{CO}$ during cooking) in the three phases (before, during, after) of all the households $(p<0.05)$ except for household 1 during the pre-intervention period, as seen in Table 4.

\subsection{Computed Stove Emissions}

The formula below was used to compute for the theoretical stove emissions:

$$
\text { During Cooking CO - Before Cooking CO = CO Stove Contribution }
$$

The 'before cooking' value represents the ambient air CO levels; if subtracted from the 'during cooking' $\mathrm{CO}$ level, it would result to the $\mathrm{CO}$ emissions the used stove produced. As seen in Table 5, the TSF emissions were higher than the FES by $5.41 \mathrm{ppm} \mathrm{CO}$, which supports the proven decrease in $\mathrm{CO}$ emissions by the lab analysis. 


\subsection{Perceived Respiratory Health Symptoms.}

Fig. 3 depicts a summary of the perceived health respiratory symptoms experienced by both groups of participants in the pre-intervention and post-intervention stages. For the control group, even without the presence of an intervention, there was an evident decrease across all symptoms, except for Cough in the Morning (remained constant). For the experimental group, a decrease in all symptoms was observed, except for Wheezing in General (remained constant) and Shortness of Breath (slightly increased).

After doing Logistic Regression, the intervention was inconclusive as seen in all the confidence intervals. No p-values were significant as well. The intervention failed to significantly reduce the incidence of the symptoms after the three-month period.

\section{CONCLUSION}

Laboratory Tests: Efficiency. The WBT for stove efficiency showed that, in the laboratory, the FES boiled water $43.16 \%$ faster, consumed $27.59 \%$ less wood per minute, heated $60.16 \%$ more water per gram of wood used, and transmitted $171.43 \%$ more heat to the pot as compared to the TSF. Compared to other reported efficiencies of fuel-efficient stoves across literature, the FES was above average in terms of thermal efficiency and specific fuel consumption.

Laboratory Tests: Emissions. The method of simulating user exposure to $\mathrm{CO}$ emissions found that the FES produced $77.18 \%$ less CO than did the TSF. The findings further proved that increased efficiency is correlated with lower emissions. The FES also proved to be above average in terms of efficiency. Based on these findings, the study proceeded having established the non-maleficence of the intervention.

Emissions Field Testing. Households of the experimental groups utilize TSFs as their current stove. The TSF CO emissions did not exceed the WHO recommendation of $28.4 \mathrm{ppm}$

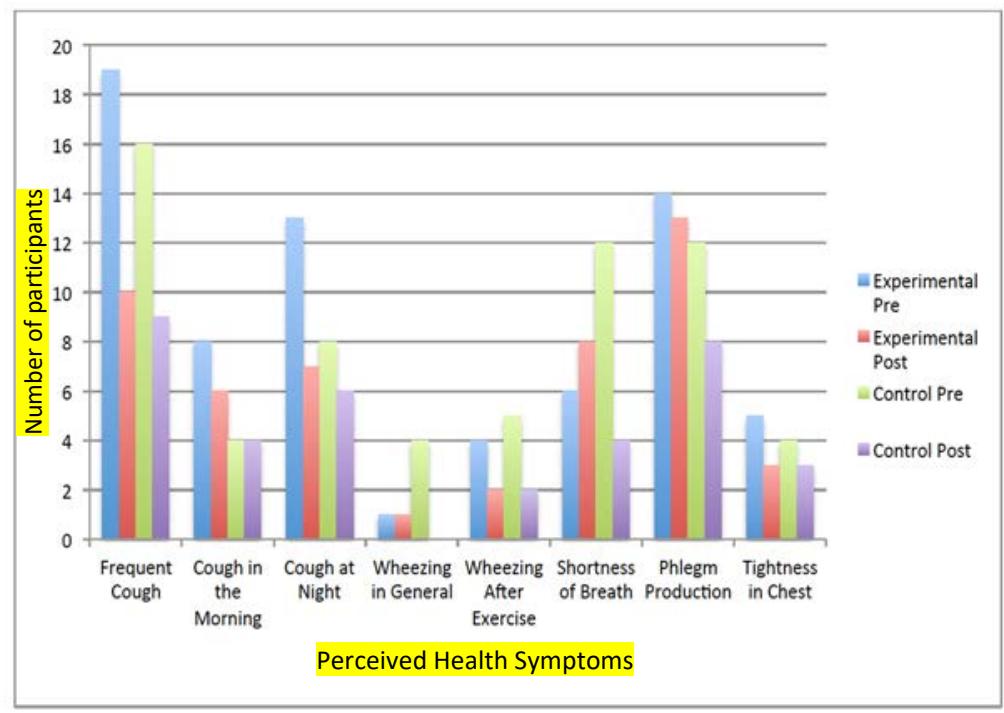

Figure 3: Perceived Respiratory Symptoms of Experimental and Control Groups. 
$\mathrm{CO}$ over an hour of exposure. The FES lowered the average $\mathrm{CO}$ emissions during cooking of all chosen households by $79.3 \%$.

Perceived Respiratory Health. Frequent cough was the symptom that was predominant in both control and experimental groups that was observed during the pre-intervention survey. After three months, even with the intervention of an FES, no significant changes in perceived respiratory symptoms indicative of acute respiratory conditions between study groups were observed. Absence of reduction in perceived respiratory health results may be due to the relatively short, although adequate, timeframe of the study. The study predicts better health outcomes in the future however given the significant reduction in emissions.

\section{ACKNOWLEDGEMENTS}

Much thanks thesis adviser Henrietta Dela Cruz, MD; project funders: the Industries Development Corporation Environment and Livelihood Development Foundation, Ateneo de Manila University Residence Halls, and Jilliane Rae Ramos; stove designer Engr. Joshua Guinto; organizations, professors, panelists, mentors, and partners in the academic and project aspects of the study: John Wong, MD, Sio Marquez, MD, Genejane Adarlo, MD and Urduja Amor from the Ateneo de Manila University, James Simpas, PhD and Genevieve Lorenzo from the Manila Observatory, Mohd Hassan, MD from the World Health Organization, Susana Castillo, MD from the Department of Health Region IV-A Office, Mylene Cayetano, $\mathrm{PhD}$ and Colleen Rosales from the UP-Institute for Environmental Science and Meteorology; for logistical support: the Philippine National Police, and the Ateneo de Manila University Residence Halls; and our partner community, Brgy. Sta. Cruz, Sto. Tomas, Batangas, Brgy. Captain Edwin Mendoza, Senior Barangay Health Worker Luzy Crusada, and the Barangay Health Workers of the area.

\section{REFERENCES}

[1] Bhattacharya, S., Albina, D. \& Salam, P.A. Emission factors of wood and charcoalfired cookstoves. Biomass and Bioenergy. 23(6), pp. 453-469, 2002. doi:10.1016/ s0961-9534(02)00072-7.

[2] Pepper, D.W. \& Carrington, D., Modelling indoor air pollution. Imperial College Press, 2009. doi:10.1142/9781848163256.

[3] Bautista, J. et al., Philippines Environment Monitor. USA: World Bank Group; 2006.

[4] National Statistical Coordination Board. FAQs on Poverty Statistics. National Statistical Coordination Board. http://www.ncsb.gov.ph/poverty/portal_ aboutPovStat. asp. Published 2011. Accessed on: 21 Oct. 2014.

[5] Arcenas, A., Bojö, J., Larsen, B.R. \& Ñunez, F.R., The economic costs of indoor air pollution: new results for Indonesia, The Philippines, and Timor-Leste. Journal of Natural Resources Policy Research, 2(1), pp. 75-93, 2010. doi:10.1080/ 19390450903350861.

[6] Maccarty, N., Ogle, D., Still, D., Bond, T. \& Roden, C., A laboratory comparison of the global warming impact of five major types of biomass cooking stoves. Energy for Sustainable Development.;12(2), pp. 56-65, 2008. doi:10.1016/s0973-0826(08) 60429-9.

[7] Saksena, S., Subida, R., Buttner, L. \& Ahmed, L., Indoor air pollution in coastal houses of Southern Philippines. Indoor and Built Environment, 16(2), pp. 159-168, 2007. doi:10.1177/1420326x07076783.

[8] Hashmi, D.R., Shareef, A., Abbasi, F.A., Ahmed, I. \& Munshi, A.B., Perception of female population health hazards associated with indoor air pollution in Karachi. 
Epidemiol Journal of Public Health and Epidemiology, 4(4), 2012. doi:10.5897/jphe11.202.

[9] Bailis, R., Ogle, D., MacCarty, N., Still, D., Smith, K.R. \& Edwards, R., Water Boiling Test, 2007. University of California, Berkeley, https://www.k4health.org/sites/ default/files/WBT Version 3.0 Jan2007a.pdf. Accessed on: 24 Jan. 2015.

[10] Oluwole, O., Ana, G.R., Arinola, G.O. et al., The effect of stove intervention on household air pollution and the respiratory health of women and children in rural Nigeria. Air Qual Atmos Health Air Quality, Atmosphere \& Health, 6(3), pp. 553-561. 2013. doi:10.1007/s11869-013-0196-9.

[11] Department of Health (DOH). The 2009 Philippine Health Statistic. Department of Health - National Epidemiology Center. http://www.doh.gov.ph/sites/default/ files/PHILIPPINE\%20HEALTH\%20STATISTICS\%202009.pdf. Published 2009. Accessed on: 15 Feb. 2014.

[12] National Statistics Office (NSO). Number of households by type of fuel used for cooking for the Philippines and its regions, provinces, and highly urbanized cities. National Statistics Office. http://www.census.gov.ph/sites/default/ files/attachments/ hsd/pressrelease/Table\%202_PR_Philippines_housing\% 20tables.pdf. Published 2010. Accessed on: 24 Nov. $201 \overline{1}$.

[13] Singh, N. \& Singh, V., Combating cough - etiopathogenesis. Supplement to Journal of the Association of Physicians of India, 61, pp. 6-7, 2013.

[14] Akpootu, D.O. et al., Comparative analysis on the performance of four selected fuel wood stoves using water boiling test. The International Journal of Engineering and Science, 3(9), pp. 26-30. www.theijes.com/papers/v3-i9/version-2/d0392026030.pdf, 2014

[15] McCracken, J. \& Smith, K., Emissions and efficiency of improved woodburning cookstoves in Highland Gatemala. Environment International, 24(7), pp. 739-747. 1998doi:10.1016/s0160-4120(98)00062-2.

[16] De Decker, K. \& Collett, J., Well-tended fires outperform modern cooking stoves. Low Tech Magazine. 2014. www.lowtechmagazine.com/2014/06/thermal-efficiencycooking-stoves.html. Accessed on: 24 Jan. 2015. 